Pesq. Vet. Bras. 36(4):303-311, abril 2016 DOI: $10.1590 / \mathrm{S} 0100-736 \mathrm{X} 2016000400009$

\title{
Características clínico-epidemiológicas, histomorfológicas e histoquímicas da esporotricose felina ${ }^{1}$
}

\begin{abstract}
Talissa Bazzi ${ }^{2}$, Stella Maris P. de Melo ${ }^{4}$, Rafael A. Fighera ${ }^{3}$ e Glaucia D. Kommers ${ }^{3 *}$
ABSTRACT.- Bazzi T., Melo S.M.P., Fighera R.A. \& Kommers G.D. 2016. [Clinical, epidemiological, histomorphological and histochemical characteristics of the feline sporotrichosis.] Características clínico-epidemiológicas, histomorfológicas e histoquímicas da esporotricose felina. Pesquisa Veterinária Brasileira 36(4):303-311. Laboratório de Patologia Veterinária, Departamento de Patologia, Centro de Ciências da Saúde, Universidade Federal de Santa Maria, Avenida Roraima 1000, Camobi, Santa Maria, RS 97105-900, Brazil. E-mail: glaukommers@yahoo.com

Sporotrichosis is a mycotic infection caused by the Sporothrix complex species, affecting mostly cats, horses, and dogs. The main objectives of this retrospective study were to characterize the histomorphological and histochemical aspects of sporotrichosis in 10 cats, and also to evaluate epidemiological and clinical aspects, and gross findings obtained from the biopsy and necropsy protocols of these ten cases, obtained from the archives of the Laboratório de Patologia Veterinária of the Universidade Federal de Santa Maria. The disease affected mostly male mongrel cats, and was mostly observed in the cutaneous disseminated form. Gross lesions were characterized by cutaneous nodules (ulcerated or not) and by ulcerated masses or plaques. By histopathology, there were a relationship between the fungal load and two patterns of inflammatory response. The first pattern was characterized by high fungal load, and most yeasts were inside of numerous macrophages with abundant, many times vacuolated cytoplasm. The amount of neutrophils ranged from mild to moderate in this pattern. The second pattern was characterized by numerous epiteliod cells and many neutrophils. The fungal load was low and most yeasts were observed in the extracellular space. The yeasts were round, oval or cigar-shaped. Several histochemical techniques, such as Grocott's silver stain, periodic Schiff acid, and Alcian blue were utilized and they made it easier to visualize, to characterize the morphology, and to quantify the organisms. The Giemsa stain allowed visualizing the agent, but it not allowed to sharply highlight them from other intralesional components. Organisms were negative for melanin granules through the Fontana-Masson stain in all cases. The histomorphological and histochemical study allowed demonstrating determinant fungal characteristics to the establishment of the diagnosis by means of this diagnostic tool.
\end{abstract}

INDEX TERMS: Feline sporotrichosis, Sporothrix spp. complex, diseases of cats, subcutaneous mycosis.

RESUMO.- Esporotricose é uma infecção fúngica causada por espécies do complexo Sporothrix, vista com maior frequência em gatos, equinos e cães. Os principais objetivos

\footnotetext{
${ }^{1}$ Recebido em 19 de outubro de 2015.

Aceito para publicação em 7 de fevereiro de 2016.

Parte da Dissertação de Mestrado do primeiro autor.

${ }^{2}$ Programa de Pós-Graduação em Medicina Veterinária, área de concentração em Patologia e Patologia Clínica Veterinária, Centro de Ciência Rurais (CCR), Universidade Federal de Santa Maria (UFSM), Av. Roraima 1000, Camobi, Santa Maria, RS 97105-900, Brasil.

${ }^{3}$ Laboratório de Patologia Veterinária, Departamento de Patologia, Centro de Ciências da Saúde (CCS), UFSM, Santa Maria, RS, Brasil. *Autor para correspondência: glaukommers@yahoo.com

${ }^{4}$ Curso de Medicina Veterinária (Bolsista PIBIC/CNPq), CCR, UFSM, Santa Maria, Brasil.
}

deste estudo retrospectivo foram caracterizar os aspectos histomorfológicos e histoquímicos da esporotricose em 10 gatos, além de avaliar os aspectos epidemiológicos, clínicos e os achados macroscópicos desses 10 casos, obtidos dos protocolos de biópsias e necropsias dos arquivos do Laboratório de Patologia Veterinária da Universidade Federal de Santa Maria. A doença acometeu predominantemente gatos machos, sem raça definida e apresentou-se principalmente na forma cutânea disseminada. As lesões macroscópicas caracterizaram-se como nódulos cutâneos (ulcerados ou não) e como massas e placas ulceradas. Na histopatologia observou-se uma relação entre a quantidade de leveduras observada e dois padrões de resposta infla- 
matória. 0 primeiro padrão caracterizou-se por numerosas leveduras que se encontravam, na sua maioria, no interior de numerosos macrófagos com citoplasma abundante e muitas vezes vacuolizado. Nesse padrão, a quantidade de neutrófilos variava de leve a moderada. 0 segundo padrão caracterizava-se por numerosas células epitelioides, infiltrado predominantemente acentuado de neutrófilos e a quantidade de leveduras era leve e estas eram observadas geralmente livres no espaço extracelular. As leveduras eram redondas, ovais ou alongadas (em forma de charuto). Foram utilizadas várias técnicas histoquímicas como a impregnação pela prata de Grocott, ácido periódico de Schiff e azul Alciano que facilitaram a visualização, caracterização da morfologia e quantificação dos organismos. A coloração de Giemsa permitiu a visualização do agente, porém não permitiu destacá-los nitidamente de outros elementos intralesionais. Os organismos foram negativos para grânulos de melanina pela coloração de Fontana-Masson em todos os casos. 0 estudo histomorfológico e histoquímico permitiu demonstrar características fúngicas determinantes para o estabelecimento do diagnóstico de esporotricose através dessa ferramenta diagnóstica.

TERMOS DE INDEXAÇÃO: Esporotricose felina, complexo Sporothrix spp., doenças de gatos, micose subcutânea.

\section{INTRODUÇÃO}

Esporotricose é uma micose subcutânea, subaguda ou crônica, causada por espécies do complexo Sporothrix. 0 complexo compreende pelo menos seis espécies (Antunes et al. 2009, Vásquez-del-Mercado et al. 2012): S. schenckii, S. brasiliensis, S. globosa, S. mexicana, S. luriei e S. pallida (Rodrigues et al. 2012). As quatro primeiras já foram isoladas no Brasil (Rodrigues et al. 2014). Esporotricose já foi descrita em humanos e em várias espécies animais que incluem gatos, cães, ratos, tatus, equinos (Téllez et al. 2014), asininos, bovinos, caprinos, suínos, hamsters, camelos, chimpanzés e aves domésticas (Ginn et al. 2007), mas é diagnosticada com maior frequência em gatos (Lacaz 2002, Ginn et al. 2007).

Sporothrix schenckii, a principal espécie associada à doença, é um fungo dimórfico (Howard 1960, Ginn et al. 2007), geofílico e sapróbio, distribuído amplamente na natureza, em solo rico em matéria orgânica em decomposição, em folhas secas, madeira, espinhos de plantas (principalmente roseiras) e musgos (Lopes-Bezerra et al. 2006, Antunes et al. 2009). A esporotricose é considerada um risco ocupacional para indivíduos que trabalham com solo, plantas ou materiais vegetais, pois a principal forma de infecção é através da inoculação do fungo devido à perfuração por espinhos ou lascas de madeira (Ginn et al. 2007, Schubach et al. 2012). Transmissão zoonótica, através de mordidas ou arranhões de ratos, tatus, gatos e cães, também ocorre (Schubach et al. 2012), sendo os gatos a espécie animal mais associada com essa forma de contágio, devido principalmente à grande quantidade de leveduras nas lesões, mas também por carrearem o agente nas unhas e na cavidade oral (Souza et al. 2006, Antunes et al. 2009, Schubach et al. 2012).
A doença é mais comum em zonas temperadas a tropicais, pois se sugere que o clima, a temperatura atmosférica e a umidade relativa do ar influenciem no crescimento do fungo no seu estado saprofítico (Díaz 1989, Ginn et al. 2007). Na América Latina, a esporotricose humana é considerada endêmica (Díaz 1989). No Brasil é endêmica no Rio de Janeiro, onde foi observado um crescimento exponencial de casos a partir do ano de 2000 (Barros et al. 2010). Neste contexto, $S$. brasiliensis (a espécie mais virulenta do complexo Sporothrix) tem sido considerado o agente predominante em gatos. Sua ocorrência é restrita às regiões Sul e Sudeste do Brasil, de acordo com a revisão de Rodrigues et al. (2014).

A classificação das formas clínicas utilizadas em humanos, cutânea localizada ou disseminada, cutâneo-linfática e extracutânea ou sistêmica (Lacaz 2002, Ginn et al. 2007, Téllez et al. 2014), é difícil de ser aplicada em cães e gatos, pois eles frequentemente têm mais de uma forma simultaneamente (Schubach et al. 2012). A rota usual de transmissão é a pele (Díaz 1989), mas também pode ocorrer por inalação, causando a forma extracutânea (Barros et al. 2010).

A infecção inicia com a inoculação do fungo, que penetra no tecido até as camadas mais profundas, onde ocorre a transição micélio-levedura; esse período dura em torno de 13 dias (Antunes et al. 2009). A levedura pode permanecer na derme e subcutâneo (local da inoculação), espalhar-se através de drenagem linfática ou disseminar-se sistemicamente pelos vasos sanguíneos (Schubach et al. 2012).

Em gatos, a esporotricose manifesta-se clinicamente como lesões cutâneas nodulares ou em placa, firmes, alopécicas e indolores que fistulam ou ulceram, liberando líquido serossanguinolento (Gross et al. 2009). Histologicamente, observa-se uma resposta inflamatória predominantemente granulomatosa, com variações principalmente quanto ao predomínio de macrófagos ou de células epiteliodes e nos demais componentes da resposta inflamatória (Miranda et al. 2013).

O diagnóstico de esporotricose baseia-se no isolamento e identificação do agente em cultura (Chomel 2014). Além disso, ela pode ser diagnosticada através da correlação de dados clínicos, epidemiológicos e laboratoriais. Dados laboratoriais incluem o exame direto (citologia do exsudato das lesões) ou o exame histopatológico (Barros et al. 2011). A técnica de imuno-histoquímica também é útil no diagnóstico, porém está disponível somente em alguns centros diagnósticos (Miranda et al. 2011), pela ausência de anticorpos comerciais. Como em alguns casos a suspeita de esporotricose ocorre somente durante o exame histopatológico e, portanto, as amostras já se encontram fixadas em formol, é importante reconhecer detalhadamente as características histomorfológicas e histoquímicas para realizar o diagnóstico. $\mathrm{O}$ objetivo deste estudo foi analisar e discutir os aspectos histomorfológicos e histoquímicos de dez casos de esporotricose diagnosticados em gatos no Laboratório de Patologia Veterinária (LPV) da Universidade Federal de Santa Maria (UFSM) e associá-los aos sinais clínicos e aos aspectos epidemiológicos. 


\section{MATERIAL E MÉTODOS}

Dez casos de esporotricose felina, diagnosticados no LPV-UFSM, foram avaliados quanto aos aspectos epidemiológicos (incluindo raça, sexo e idade), histórico clínico e alterações clínico-patológicas. Esses casos foram validados através do exame histopatológico, pela evidenciação do agente nas lesões somado a sua morfologia característica e às suas propriedades tintoriais histoquímicas. Para isso, foram incluídos casos em que os fungos apresentavam os seguintes critérios morfológicos: 1) ocorrer na forma de levedura; 2) ser oval, redondo ou alongado ("forma de charuto"); 3 ) ter entre 2 e $8 \mu \mathrm{m}$; e 4) apresentar espécimes com brotamentos de base estreita, os quais podem também ser tubulares. Esses critérios foram estabelecidos com base em Lacaz (2002), Ginn et al. (2007), Gross et al. (2009), Guarner \& Brandt (2011), Schubach et al. (2012) e Mahajan (2014).

Informações detalhadas foram obtidas a partir dos laudos de biópsias (Gatos 1-5) ou de necropsias (Gatos 6-10). Os espécimes provenientes de necropsias ou biópsias haviam sido fixados em formol tamponado a $10 \%$ e processados rotineiramente para histopatologia. Seções de $3 \mu \mathrm{m}$, coradas com hematoxilina e eosina (HE), foram reavaliadas para quantificar as leveduras, classificar e determinar a intensidade da resposta inflamatória em cada caso. Utilizaram-se também técnicas histoquímicas como a impregnação pela prata de Grocott (GMS), ácido periódico de Schiff (PAS), azul alciano (AA), Giemsa e Fontana-Masson (FM) para melhor visualização e, consequentemente, caracterização das leveduras. As seções foram analisadas pelas técnicas histoquímicas em duas magnificações (400x e 1000x). A quantidade de organismos foi classificada em leve (+; quando se observavam até cinco organismos por campo de 1000x), moderada (++; 6 a 50 organismos por campo de 1000x) ou acentuada (+++; mais de 50 organismos por campo de 1000x). As imagens das leveduras foram obtidas através de um microscópio Olympus BX51, com câmera digital DP21, controlada pelo programa Olympus CellSens $^{\circledR}$.

\section{RESULTADOS}

Os dados epidemiológicos encontram-se detalhados no Quadro 1. Sete gatos não tinham raça definida (SRD), dois eram de raça e em um a raça não foi informada. Do total de dez gatos, oito eram machos e dois eram fêmeas. Em cinco casos havia informação de serem machos inteiros (Gatos 6-10). A média da idade dos gatos foi de cinco anos e seis tinham mais de cinco anos.
Os históricos clínicos dos Gatos 1, 6, 7 e 10 continham informações de que gatos de vizinhos haviam sido diagnosticados com esporotricose. Todos esses eram da mesma vizinhança. 0 Gato 2 foi arranhado por outro gato e depois surgiram as lesões cutâneas. As lesões no Gato 3 tinham evolução de sete meses; no Gato 6, de um mês; e no Gato 7 , de um ano. Os históricos dos demais gatos não tinham informações sobre a evolução clínica. Em relação ao estado corporal, o Gato 3 tinha histórico de emagrecimento. Os Gatos 6, 7 e 10 estavam em bom estado, e os Gatos 8 e 9 estavam em mau estado corporal.

Quanto ao tratamento, as seguintes situações foram observadas nos casos estudados: (a) não havia histórico sobre tratamento específico para esporotricose (Gatos 1, 2, 3, 5, 8 e 9); (b) o Gato 4 foi tratado sem sucesso, porém não foi especificado o tipo de tratamento; (c) o Gato 6 foi tratado com antibiótico; (d) o Gato 10 recebeu tratamento específico para esporotricose (itraconazol), porém sem resposta satisfatória; (e) o Gato 7 tinha histórico de nunca ter sido tratado.

A quantidade e localização das lesões e as formas clínicas estão detalhadas no Quadro 1. Os sinais clínicos e as lesões macroscópicas foram observados como nódulos (ulcerados ou não), e como massas e placas ulceradas. Frequentemente, as áreas ulceradas eram recobertas por crostas, muitas vezes espessas (Fig.1, 2, 3 e 4).

Dos dez casos, cinco (Gatos 1, 2, 7, 9 e 10) tinham suspeita clínica de esporotricose. No Gato 2 havia diagnóstico de esporotricose pela citologia. A cultura foi realizada em amostras de pele dos Gatos 7, 9 e 10, resultando positiva no Gato 9 e negativa nos Gatos 7 e 10.0 desfecho dos casos de biópsias não foi determinado. Dos casos de necropsias, somente o Gato 8 teve morte espontânea; os demais foram submetidos à eutanásia.

Todos os casos foram diagnosticados pelas alterações histológicas e pela evidenciação do agente intralesional, somado à sua morfologia e às suas propriedades tintoriais histoquímicas características. Na histopatologia havia infiltrado inflamatório que se estendia da derme superficial até a profunda, por vezes atingindo o tecido subcutâneo. 0 infiltrado inflamatório caracterizava-se pela presença de diferentes proporções de macrófagos, células (macrófagos) epitelioides, neutrófilos, linfócitos e plasmócitos. Este infil-

Quadro 1. Dados epidemiológicos e alterações clínico-patológicas de 10 casos de esporotricose felina

\begin{tabular}{|c|c|c|c|c|c|}
\hline Gato $\left(\mathrm{n}^{\mathrm{o}}\right)$ & Raça & Sexo & Idade & Quantidade e localização das lesões cutâneas & Forma clínica \\
\hline 1 & SRD & M & $8 \mathrm{a}$ & Lesão única (pata - coxim) & Cutânea localizada* \\
\hline 2 & SRD & $\mathrm{F}$ & $4 \mathrm{~m}$ & Múltiplas lesões (NI) & Cutânea disseminada* \\
\hline 3 & Siamês & $\mathrm{F}$ & $8 \mathrm{a}$ & Múltiplas lesões (NI) & Cutânea disseminada* \\
\hline 4 & $\mathrm{NI}$ & M & $2 \mathrm{a}$ & Múltiplas lesões (face) & Cutânea disseminada* \\
\hline 5 & Persa & M & $6 \mathrm{a}$ & Múltiplas lesões (NI) & Cutânea disseminada* \\
\hline 6 & SRD & M & $3 \mathrm{a}$ & Múltiplas (face, periocular, periauricular, orelhas e escápulas) & Cutânea disseminada \\
\hline 7 & SRD & M & $8 \mathrm{a}$ & Múltiplas (focinho, orelha, membros anteriores e cauda) & Cutânea disseminada \\
\hline 8 & SRD & M & $10 \mathrm{a}$ & $\begin{array}{l}\text { Múltiplas (face, periocular, orelha, focinho, membros } \\
\text { anteriores e posterior direito, abdômen ventral) }\end{array}$ & Cutânea disseminada \\
\hline 9 & SRD & M & $1 \mathrm{a}$ & Múltiplas (orelha, periocular e membros posteriores) & Cutânea disseminada \\
\hline 10 & SRD & M & $6 \mathrm{a}$ & $\begin{array}{l}\text { Múltiplas (face, lábio, orelha, periauricular, focinho, } \\
\text { região lombar, região lateral ao saco escrotal, } \\
\text { membros anteriores e posterior direito) }\end{array}$ & Cutânea disseminada \\
\hline
\end{tabular}

$\overline{\mathrm{SRD}}=$ sem raça definida, $\mathrm{NI}=$ não informado, $\mathrm{M}=$ macho, $\mathrm{F}=$ fêmea, $\mathrm{a}=$ anos, $\mathrm{m}=$ meses. ${ }^{*}=$ No momento do diagnóstico histopatológico. 

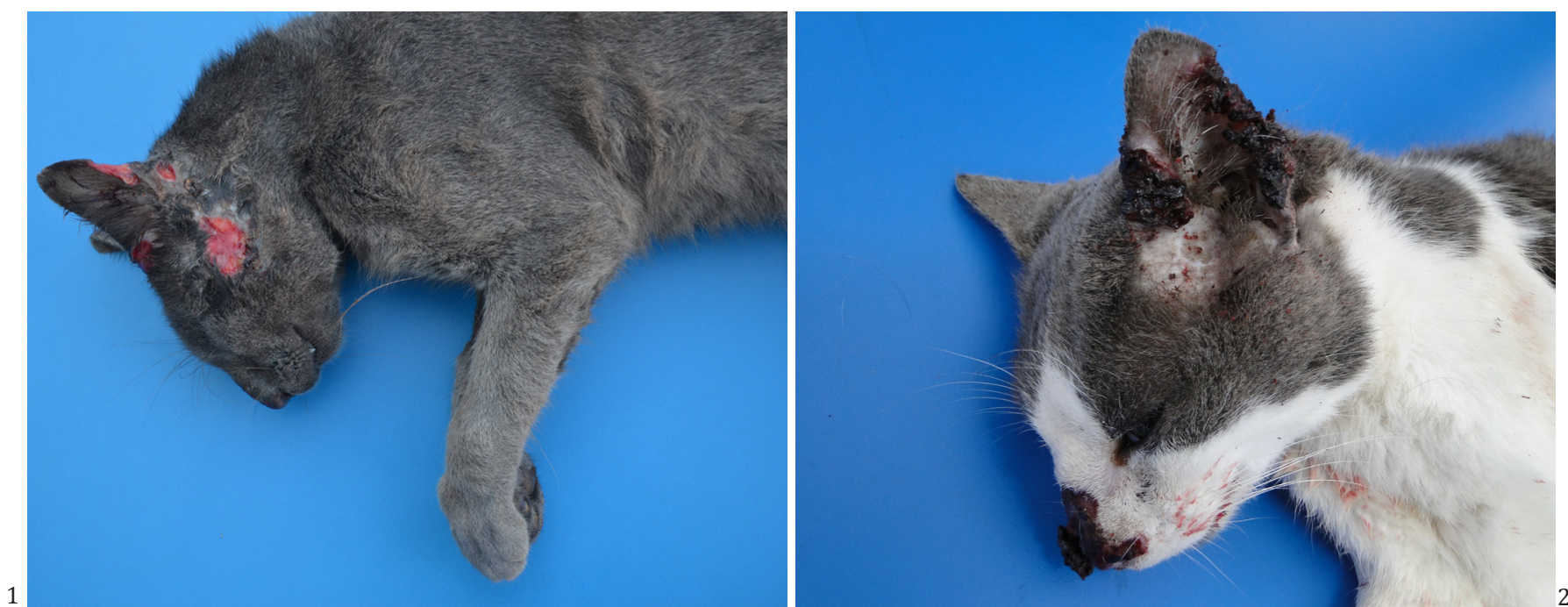

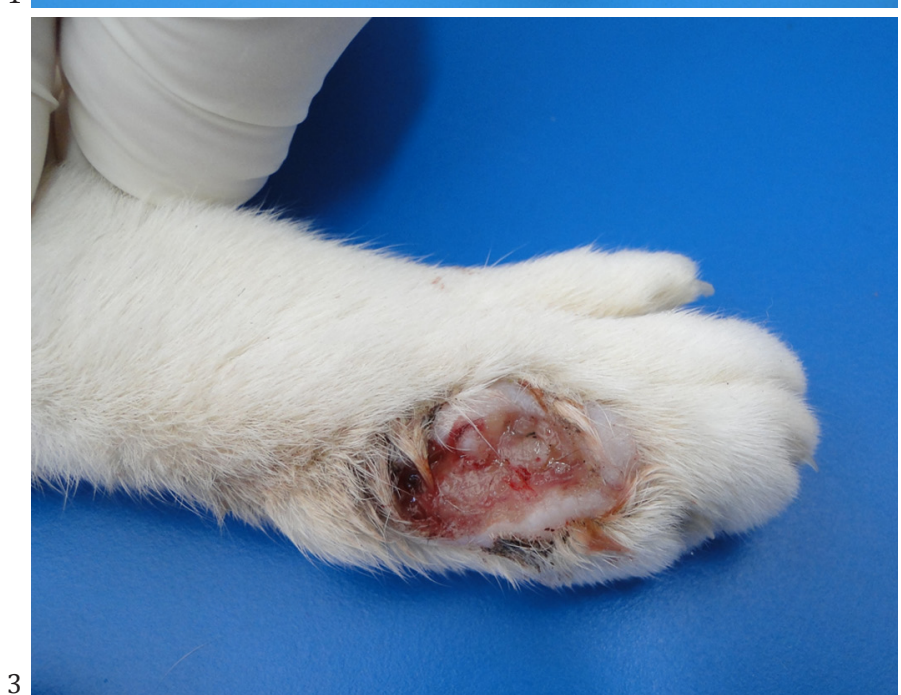

Fig.1. Placas ulceradas, bem circunscritas, eritematosas, circulares a ovaladas e úmidas (exsudato), localizadas na borda lateral da orelha, na base medial da orelha e na lateral da face, na esporotricose felina (Gato 10).

Fig.3. Gato 7. Placa ulcerada, circular e bem delimitada na face dorso-lateral da região metacarpiana, na esporotricose felina (Gato 7).

trado era distribuído de forma multifocal (algumas vezes nodular), coalescente ou difuso. Observou-se uma relação entre a quantidade de leveduras observada no HE e dois possíveis padrões de inflamação. 0 primeiro padrão (Gatos $1,2,4,5,6$ e 9) caracterizava-se pela presença de numerosas leveduras (++ para o Gato $1 \mathrm{e}+++$ para os demais) que se encontravam, na sua maioria, no interior de numerosos macrófagos com citoplasma abundante e muitas vezes vacuolizado (Fig.5 e 6). A quantidade de neutrófilos variava de leve a moderada e havia infiltrado, geralmente leve, de linfócitos e plasmócitos. 0 segundo padrão (Gatos 3, 7, 8 e 10) caracterizava-se por grande quantidade de células epitelioides, infiltrado acentuado de neutrófilos e escassos linfócitos (Fig.7 e 8). A quantidade de leveduras nesses casos era leve $(+)$ e estas eram observadas geralmente livres.

Os organismos foram quantitativamente identificados de forma semelhante nas colorações de HE, PAS, AA e GMS (Quadro 2). Porém, quando a quantidade de leveduras era

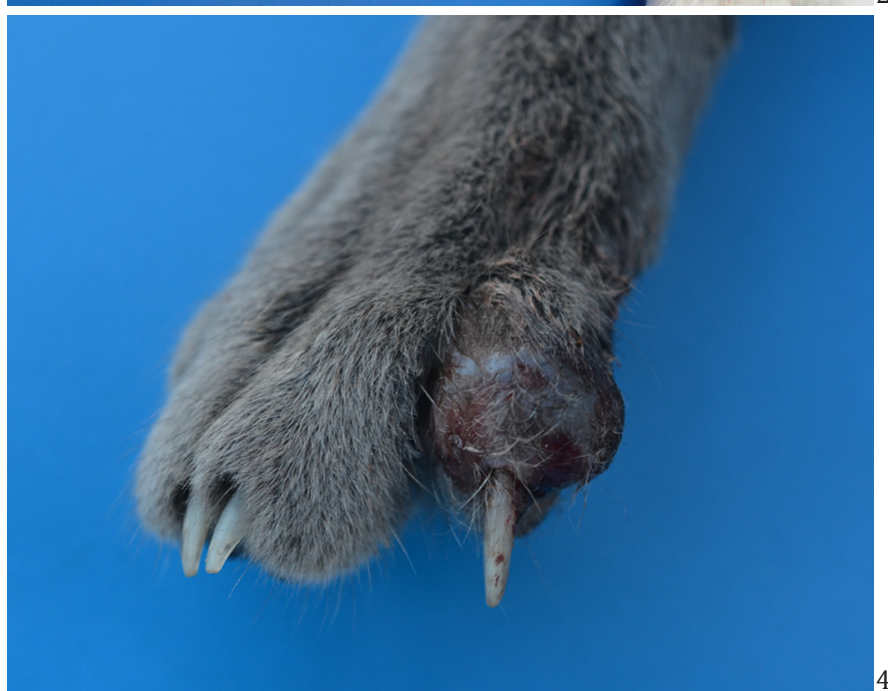

Fig.2. Lesão ulcerativa e crostosa comprometendo todo o plano nasal, se estendendo da ponte ao espelho nasal, e na orelha esquerda (base e borda), na esporotricose felina (Gato 7).

Fig.4. Nódulo digital alopécico que caracteriza paroníquia, na esporotricose felina (Gato 10).

leve (+), a quantificação dos organismos foi muito facilitada pelos métodos do PAS, AA e GMS (Fig.9, 10, 11, 12, 13 e 14). Qualitativamente, as colorações de PAS, AA e GMS permitiram uma

Quadro 2. Quantificação de organismos fúngicos através de técnicas histoquímicas em 10 casos de esporotricose felina

\begin{tabular}{ccccc}
\hline Gato $\left(\mathrm{n}^{\circ}\right)$ & HE & PAS & AA & GMS \\
\hline 1 & ++ & ++ & ++ & ++ \\
2 & +++ & +++ & +++ & +++ \\
3 & + & + & + & + \\
4 & +++ & +++ & +++ & +++ \\
5 & +++ & +++ & +++ & +++ \\
6 & +++ & +++ & +++ & +++ \\
7 & + & + & + & + \\
8 & + & + & + & + \\
9 & +++ & +++ & +++ & +++ \\
10 & + & + & + & +
\end{tabular}

$\overline{\mathrm{HE}}=$ hematoxilina-eosina, $\mathrm{PAS}=$ ácido periódico de Schiff, $\mathrm{AA}=$ azul alciano, GMS = impregnação pela prata de grocott, $+=$ leve,$++=$ moderada, $+++=$ acentuada. 

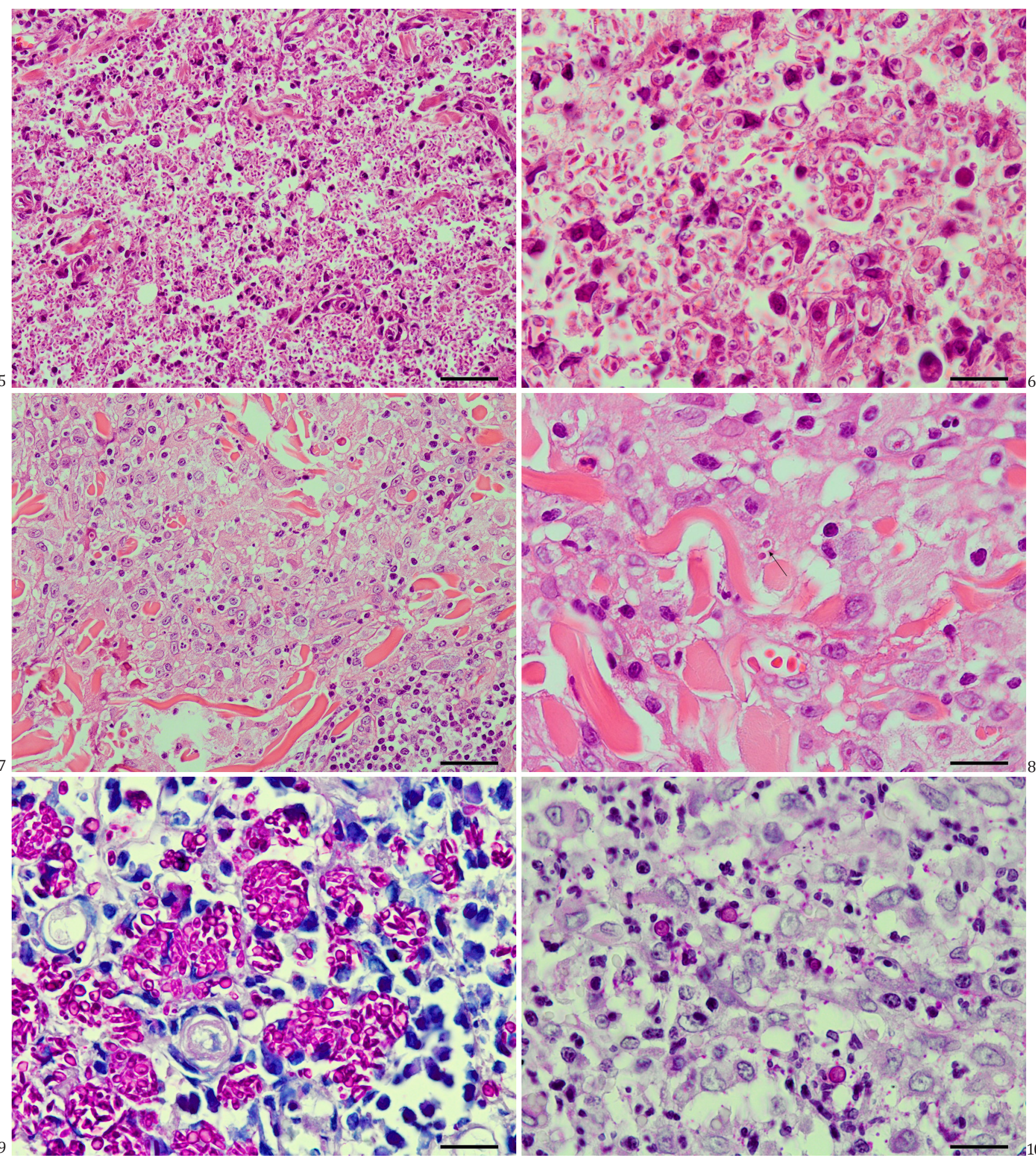

Fig.5. Infiltrado inflamatório composto de macrófagos com citoplasma abundante e preenchido por numerosas leveduras. Há leve quantidade de neutrófilos esparsos, na esporotricose felina (Gato 6). HE, obj.40x.

Fig.7. Infiltrado inflamatório composto de numerosas células epitelioides e poucos neutrófilos e linfócitos, na esporotricose felina (Gato 3). HE, obj.40x.

Fig.9. Numerosas leveduras coradas em rosa, predominantemente no interior de macrófagos, na esporotricose felina (Gato 4). Mesmo padrão de lesão das Fig.5 e 6. Ácido periódico de Schiff, obj.100x.

Fig.6. Macrófagos preenchidos por leveduras redondas, ovais e alongadas (em forma de charuto). Há exemplares de leveduras extracelulares, na esporotricose felina (Gato 6). HE, obj.100x.

Fig.8. Escassa quantidade de leveduras (seta) em meio às células epiteloides, na esporotricose felina (Gato 3). HE, obj.100x.

Fig.10. Escassas leveduras coradas em rosa em meio ao infiltrado inflamatório, na esporotricose felina (Gato 7). Mesmo padrão de lesão das Fig.7 e 8. Ácido periódico de Schiff, obj.100x. 


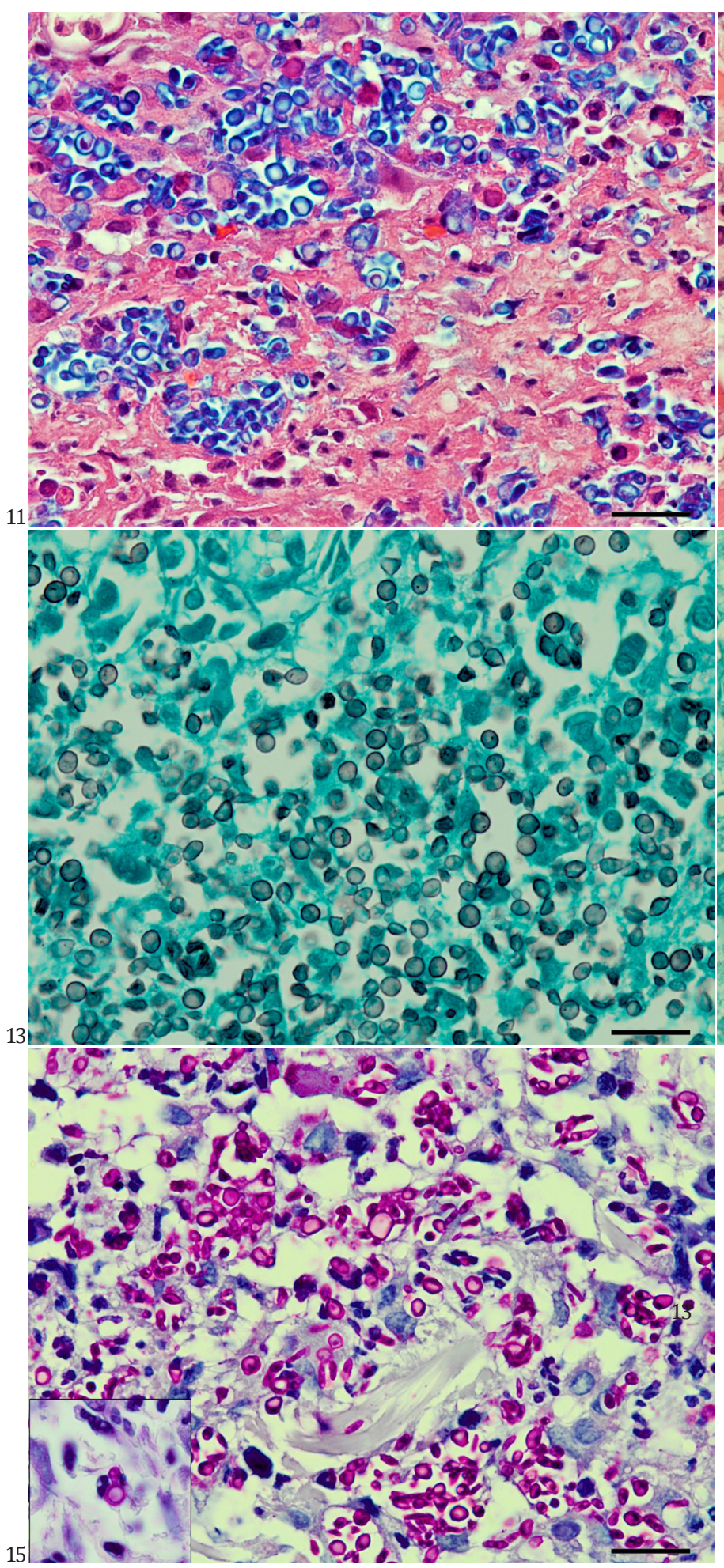

melhor evidenciação da morfologia das leveduras, quando comparadas ao HE.

As leveduras eram redondas (maioria), ovais, ou alongadas (em forma de charuto), com 2 a $8 \mu$ m (Fig.15). Os brotamentos foram melhor identificados nas colorações de PAS e GMS. Os brotamentos foram vistos como projeções alongadas (tubulares) ou em base estreita a partir da levedura redonda (Fig.15 - detalhe).

A coloração de Giemsa permitiu a visualização do agen-

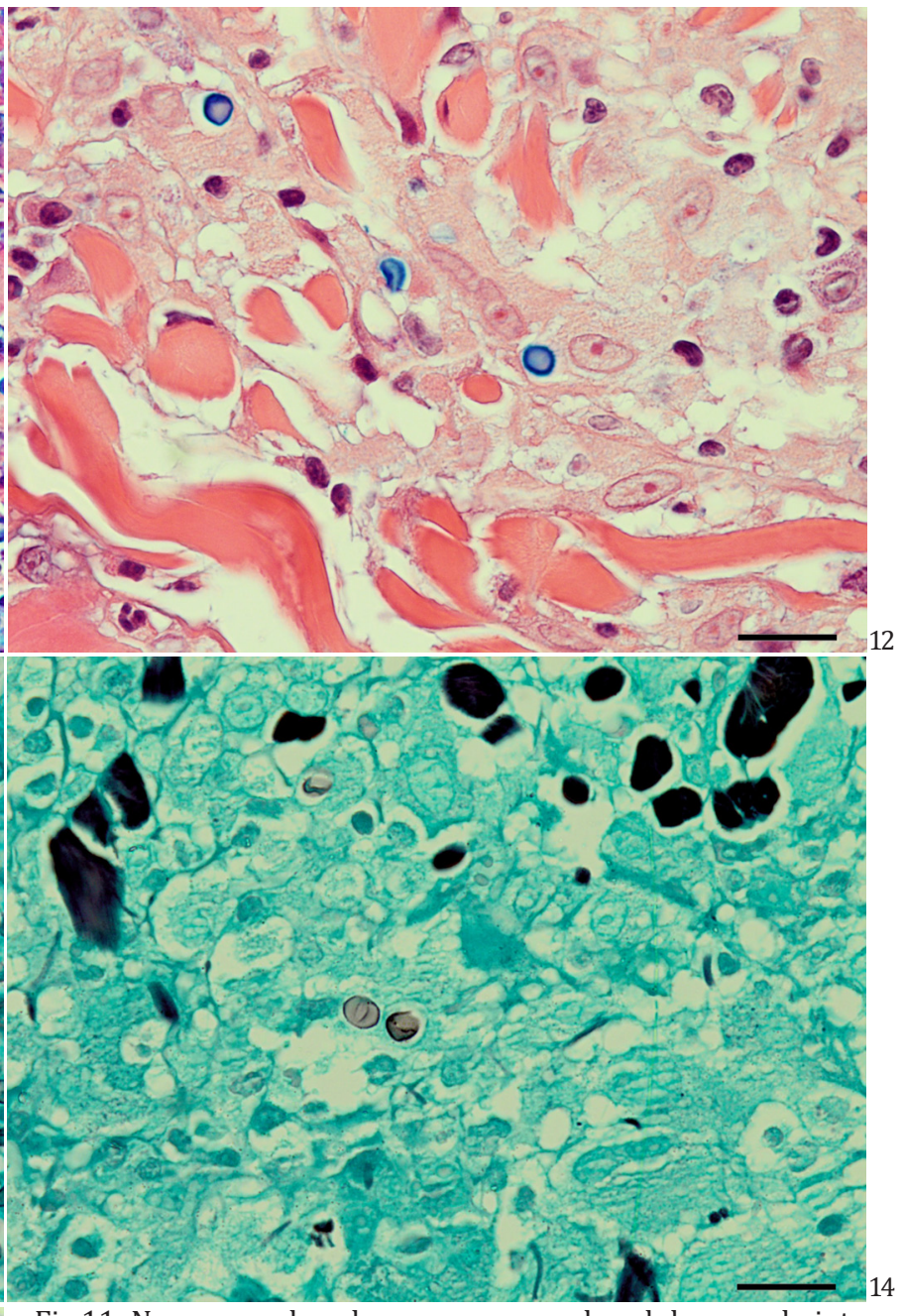

Fig.11. Numerosas leveduras com a parede celular corada intensamente em azul, na esporotricose felina (Gato 4). Mesmo padrão de lesão das Fig.5 e 6. Azul alciano, obj.100x.

Fig.12. Escassas leveduras intensamente coradas em azul em meio ao infiltrado de células epitelioides, na esporotricose felina (Gato 3). Mesmo padrão de lesão das Fig.7 e 8 . Azul alciano, obj.100x.

Fig.13. Numerosas leveduras marrom-acinzentadas, fortemente impregnadas pela prata, na esporotricose felina (Gato 6). Mesmo padrão de lesão das Fig.5 e 6. Impregnação pela prata de Grocott, obj.100x.

Fig.14. Raras leveduras marrom-acinzentadas, na esporotricose felina (Gato 3). Mmesmo padrão de lesão das Fig.7 e 8. Impregnação pela prata de Grocott, obj.100x.

Fig.15. Leveduras redondas, ovais e alongadas (em forma de charuto) coradas em rosa. Há variação no tamanho principalmente das leveduras redondas, na esporotricose felina (Gato 4). No detalhe há um brotamento em base estreita. Ácido periódico de Schiff, obj.100x.

te, porém não permitiu destacá-los nitidamente de debris celulares e do infiltrado inflamatório, dificultando a visualização quando havia poucas leveduras. Em todos os casos não foi possível detectar a presença de melanina nos organismos através da coloração de FM.

\section{DISCUSSÃO}

Por meio deste estudo retrospectivo, foi possível caracterizar aspectos epidemiológicos e clínico-patológicos da es- 
porotricose em dez gatos. Quanto aos dados epidemiológicos observou-se que a grande maioria dos gatos eram SRD, o que foi consistente com as observações de outros autores (Rossi et al. 2013a, Rossi et al. 2013b). Cabe ressaltar que na área de abrangência do LPV-UFSM, gatos SRD são muito representados.

Quanto ao sexo, 8/10 gatos eram machos, sendo cinco inteiros. Essa tendência da esporotricose em afetar mais machos (Miranda et al. 2013) deve-se ao maior acesso ao ambiente extradomiciliar (Gross et al. 2009), o que resulta em maior probabilidade de os machos se envolverem em brigas por fêmeas ou por território, principalmente aqueles não castrados (Schubach et al. 2012). Além disso, os gatos possuem comportamentos como cobrirem seus dejetos com terra, lutar com outros animais e escalar e afiar as unhas em árvores (Larsson et al. 1989, Antunes et al. 2009, Schubach et al. 2012), o que os predispõe a se tornarem portadores do fungo e o dispersar pelo ambiente (Schubach et al. 2012). Vale salientar que neste estudo quatro gatos machos eram da mesma vizinhança, indicando a possibilidade de disseminação da doença através da interação animal ou de uma mesma fonte ambiental.

Em todos os casos de necropsias deste estudo havia somente manifestação cutânea da doença, ocorrendo principalmente a forma cutânea disseminada. Não foi possível saber o desfecho dos casos remetidos como biópsias. As duas formas cutâneas (localizada e disseminada) têm sido descritas como as mais frequentes em gatos (Antunes et al. 2009), porém há controvérsias quanto a qual das duas seria a mais prevalente (Rossi et al. 2013b, Miranda et al. 2013). Nos gatos aqui estudados não foi possível observar uma relação entre a multiplicidade de lesões cutâneas e a carga fúngica intralesional, pois $9 / 10$ gatos tinham múltiplas lesões cutâneas e cinco desses tinham alta carga fúngica, enquanto quatro tinham poucas leveduras nos tecidos. Entretanto, em um estudo com 86 gatos havia indicação de que um maior número de lesões cutâneas observadas clinicamente estava associado com uma maior carga fúngica (Miranda et al. 2013).

Os principais sinais clínicos/lesões macroscópicas caracterizavam-se por lesões cutâneas únicas ou múltiplas, geralmente ulceradas e crostosas. A lesão inicial de esporotricose caracteriza-se pela formação de nódulos subcutâneos, firmes, que lentamente tornam-se macios ou maleáveis ("gomosos"). À medida que isso ocorre, passam a drenar conteúdo seroso ou purulento e progridem para a formação de úlceras marcadamente exsudativas, com bordas ligeiramente definidas (Larsson et al. 1989). A evolução da doença é geralmente grave (Schubach et al. 2012).

Apesar de que em cinco gatos deste estudo retrospectivo havia suspeita clínica de esporotricose, somente em três deles havia informação sobre o envio de amostras para cultura micológica. A cultura e identificação de espécies de Sporothrix é considerada por muitos autores como sendo a técnica padrão-ouro de diagnóstico (Schubach et al. 2012, Mahajan 2014). Entretanto, a falta de suspeita clínica faz com que amostras de biópsias e mesmo de necropsias sejam conservadas apenas em formol, impossibilitando o envio para exame micológico (Miranda et al. 2011). Nos casos em que amostras não foram submetidas para cultura, a cultura resultou negativa ou ocorreu contaminação da cultura (com microorganismos saprófitas), os critérios da morfologia fúngica intratecidual são utilizados como ferramenta diagnóstica (Jensen et al. 1996). Nos gatos, os organismos fúngicos são considerados altamente característicos nos tecidos, permitindo a confirmação do diagnóstico definitivo de esporotricose (Gross et al. 2009).

As regiões mais afetadas nos gatos estudados foram a cabeça e membros, seguidos de cauda, abdômen, região lombar e região lateral ao saco escrotal. Na literatura, as áreas mais afetadas são a cabeça, especialmente focinho e região periocular (Schubach et al. 2012), a cauda e os membros (Antunes et al. 2009, Gross et al. 2009, Schubach et al. 2012). Esses locais são considerados os mais afetados durante as brigas (Rosser \& Dunstan 2006).

Neste estudo ficou bem caracterizada a ocorrência de dois padrões de lesão histológica nos dez casos analisados. Nesses possíveis padrões, o tipo de infiltrado inflamatório estava relacionado com uma diferença marcada na quantidade de leveduras intralesionais. O padrão com predomínio de macrófagos estava associado com uma carga fúngica alta e o padrão com predomínio de células epitelioides estava associado com uma carga fúngica baixa. Essa observação deve ser ressaltada, pois em grande parte da literatura veterinária somente o padrão inflamatório macrofágico associado à alta carga fúngica é mencionado na esporotricose felina (Marques et al. 1993, Ginn et al. 2007, Antunes et al. 2009). Porém, o patologista deve estar alerta para a ocorrência de um padrão com predomínio de células epitelioides e uma carga fúngica bastante baixa, a qual muitas vezes é melhor detectada por meio de técnicas histoquímicas adicionais à coloração de HE. Baixa carga fúngica tecidual em caso com cultura positiva para Sporothrix já foi observada, conforme revisado por Gross et al. (2009). Isso demonstra que nem sempre os gatos apresentam um alto potencial zoonótico como geralmente afirmado (Souza et al. 2006, Antunes et al. 2009, Gross et al. 2009, Schubach et al. 2012) e podem ter lesões que se assemelham a esporotricose canina (Gross et al. 2009), dificultando sobremaneira o diagnóstico.

A observação de uma relação inversa entre a intensidade de neutrófilos e a carga fúngica tecidual, com uma alta proporção de casos apresentando alta carga fúngica juntamente com intensidade leve a moderada de neutrófilos foi um aspecto característico da esporotricose felina em 86 casos avaliados (Miranda et al. 2013) e também foi observada nos gatos aqui estudados. Conforme discutido por Miranda et al. (2013), em camundongos, a maior eficiência da fagocitose fúngica pelos neutrófilos nessa espécie poderia justificar uma baixa carga fúngica em lesões ricas em neutrófilos.

Quatro gatos (Gato 3, 7, 8 e 10) com mais de cinco anos tinham carga fúngica intralesional leve. Há um estudo que diz que animais acima de cinco anos são mais resistentes à infecção (Miranda et al. 2013), porém neste estudo também havia gatos com mais de cinco anos apresentando carga fúngica moderada a alta (Gatos 1 e 5). Chama a atenção o fato de que o padrão inflamatório com predomínio de células 
epitelioides (com baixa carga fúngica) foi observado nesses mesmos quatro gatos. Associação do padrão inflamatório com células epitelioides com a idade acima de cinco anos também foi observada anteriormente (Miranda et al. 2013).

0 número de gatos analisados neste estudo não permitiu estabelecer se o padrão inflamatório constituído por células epitelioides e infiltrado inflamatório neutrofílico acentuado estaria relacionado com um melhor controle da doença. Em um estudo com 86 gatos, os resultados da histopatologia sugeriram uma relação entre uma resposta inflamatória bem organizada (com formação de granulomas e presença de células epitelioides) e o controle da carga fúngica, bem como sua associação com a condição geral do animal e a apresentação clínica da doença. Entretanto, não foi possível determinar se as diferentes apresentações clínicas, a carga fúngica e o perfil inflamatório estavam relacionados à infecção por diferentes espécies do complexo Sporothrix ou a diferentes susceptibilidades dos gatos (Miranda et al. 2013).

A reação de Splendore-Hoeppli circundando as leveduras tem sido descrita como muito frequente na esporotricose humana (Vásquez-del-Mercado et al. 2012, Mahajan 2014). Porém, não tem sido descrita na esporotricose felina (Miranda et al. 2009, Schubach et al. 2012) e também não foi vista nos gatos deste estudo.

A utilização de um painel histoquímico permitiu ampliar o uso desta ferramenta diagnóstica na detecção de Sporothrix intralesionais. Neste painel, as colorações de PAS, GMS e AA foram as que melhor permitiram a visualização do agente, a identificação da sua morfologia e dimensões, bem como a sua distribuição intra e extracelular. A observação através da objetiva de imersão (aumento de 1000x) foi extremamente útil na localização das leveduras quando estas eram escassas, na identificação dos brotamentos e de detalhes morfológicos das leveduras.

Classicamente, as colorações de PAS e GMS são utilizadas na detecção de Sporothrix spp. (Marques et al 1992, Lacaz 2002, Gross et al. 2009, Miranda et al. 2009, Barros et al. 2011). Entretanto, a técnica do AA não tem sido mencionada para este fim. Nos casos aqui estudados, o AA se mostrou extremamente útil na detecção do agente, por corar fortemente em azul a parede da levedura, contrastando com as demais estruturas teciduais. Esta técnica já tinha sido utilizada na detecção da cápsula de polissacarídeos e da parede celular de Cryptococcus spp. em outro estudo (Galiza et al. 2014).

Por outro lado, a técnica de Giemsa (histológico), por ser monocromática, permitiu a visualização do agente, mas não o destacou do contexto de debris celulares e do infiltrado inflamatório. Essa coloração tem sido indicada para o exame do exsudato (pus) das lesões na citologia (Lacaz 2002).

A técnica de FM foi utilizada neste painel numa tentativa de detecção de grânulos de melanina nas leveduras, considerando que a melanina tem sido descrita como um dos fatores importantes de virulência de espécies de Sporothrix (Romero-Martinez et al. 2000). Entretanto, em nenhum dos casos houve detecção da melanina, fazendo pensar que as quantidades são bastante pequenas para a sensibilidade desta técnica (Kwon-Chung et al. 1981).
Adicionalmente, a negatividade no FM foi um fator importante para distinguir de criptococose, que é considerado o principal diagnóstico diferencial histopatológico em gatos (Gross et al. 2009), pois Cryptococcus spp. se mostram fortemente positivos nesta coloração (Kwon-Chung et al. 1981, Galiza et al. 2014). As diferenças marcantes entre Sporothrix spp. e Cryptococcus spp. estão no tamanho das leveduras (maiores), na presença da cápsula polissacarídica e de melanina na parede fúngica deste outro fungo (Kwon-Chung et al. 1981, Galiza et al. 2014). Outros diagnósticos diferenciais incluem candidíase, histoplasmose, leishmaniose, síndrome leproide felina e o carcinoma de células escamosas (em gatos despigmentados) (Larsson et al. 1989, Antunes et al. 2009, Gross et al. 2009, Guarner \& Brandt, 2011).

\section{CONCLUSÕES}

Este estudo retrospectivo de 10 casos de esporotricose em gatos permitiu concluir que: gatos machos foram os mais acometidos; as lesões cutâneas eram múltiplas na maioria dos gatos e ocorriam principalmente na cabeça, membros e cauda; a avaliação histopatológica permitiu classificar as lesões em dois possíveis padrões relacionados com cargas fúngicas de intensidades diferentes e com infiltrados inflamatórios com componentes celulares distintos; devido ao elevado número de casos atípicos (segundo padrão de lesão) observados, estudos adicionais são necessários para elucidar a patogênese dessas lesões.

As técnicas histoquímicas utilizadas permitiram observar características morfológicas e tintoriais determinantes no diagnóstico de esporotricose felina, com destaque para a técnica do azul Alciano.

Agradecimentos.- T. Bazzi (mestrado) é bolsista do CNPq. G.D. Kommers é bolsista de Produtividade do CNPq (PQ-2; Processo nº307555/20135). O projeto é financiado pelo CNPq - Edital Universal (Processo $n^{\circ}$ 474839/2012-5).

\section{REFERÊNCIAS}

Antunes T.A., Meinerz A.R.M., Martins A.A., Madrid I.M. \& Nobre M.O. 2009. Esporotricose, p.109-121. In: Meireles M.C.A. \& Nascente P.S. (Orgs), Micologia Veterinária. Ed. Universitária UFPel, Pelotas.

Barros M.B.L., Schubach T.P., Coll J.O., Gremião I.D., Wanke B. \& Schubach A. 2010. Esporotricose: a evolução e os desafios de uma epidemia. Revta Panam. Salud Publica 27(6):455-460.

Barros M.B.L., Paes R.A. \& Schubach A.O. 2011. Sporothrix schenckii and Sporotrichosis. Clin. Microbiol. Rev. 24(4):633-654.

Chomel B.B. 2014. Emerging and re-emerging zoonoses of dogs and cats. Animals 4:434-445.

Díaz I.A.C. 1989. Epidemiology of sporotrichosis in Latin America. Mycopathologia 108:113-116.

Ginn P.E., Mansell J.E.K.L. \& Rakich P.M. 2007. Sporotrichosis, p.703-704. In: Jubb K.V.F., Kennedy P.C. \& Palmer N. (Eds), Pathology of Domestic Animals. Vol.1. 5th ed. Elsevier, Philadelphia.

Galiza G.J.N., Silva T.M., Caprioli R.A., Tochetto C., Rosa F.B., Fighera R.A. \& Kommers G.D. 2014. Características histomorfológicas e histoquímicas determinantes no diagnóstico da criptococose em animais de companhia. Pesq. Vet. Bras. 34(3):261-269.

Gross T.L., Ihrke P.J., Walder E.J. \& Affolter V.K. 2009. Esporotricose, p.289292. In: Ibid. (Eds), Doenças de pele do cão e do gato. $2^{\text {a }}$ ed. Roca, São Paulo. 
Guarner J. \& Brandt M.E. 2011. Histopathologic diagnosis of fungal infections in the 21st century. Clin. Microbiol. Rev. 24(2):247-280.

Howard D.H. 1960. Dimorphism of Sporotrichum schenckii. J. Bacteriol. 81:464-469.

Jensen H.E., Aalbaek B., Lind P. \& Krogh H.V. 1996. Immunohistochemical diagnosis of systemic bovine zygomycosis by Murine Monoclonal Antibodies. Vet. Pathol. 33(2):176-183.

Kwon-Chung K.J., Hill W.B. \& Bennett J.E. 1981. New, special stain for histopathological diagnosis of cryptococcosis. J. Clin. Microbiol. 13:383-387.

Lacaz C.S. 2002. Esporotricose e outras Micoses Gomosas, p.479-487. In: Lacaz C.S., Porto E., Martins J.E.C., Heis-Vaccari E.M. \& Takahashi de Melo N. (Eds), Tratado de micologia médica Lacaz. 9ạ ed. Savier, São Paulo.

Larsson C.E., Gonçalves M.A., Araujo V.C., Dagli M.L.Z., Correa B. \& Fava Neto C. 1989. Esporotricosis felina: aspectos clínicos e zoonótico. Rev. Inst. Med. trop. São Paulo. 31(5):351-358.

Lopes-Bezerra L.M., Schubach A. \& Costa R.O. 2006. Sporothrix schenckii and sporotrichosis. An. Acad. Bras. Ciênc. 78(2):293-308.

Mahajan V.K. 2014. Sporotrichosis: an overview and therapeutic options. Dermatol. Res. Pract. 2014:1-13.

Marques M.E.A., Coelho K.I.R., Sotto M.N. \& Bacchi C.E. 1992. Comparison between histochemical and immunohistochemical methods for diagnosis of sporotrichosis. J. Clin. Pathol. 45:1089-1093.

Marques S.A., Franco S.R.V.S., Camargo R.M.P., Dias L.D.F., Haddad Júnior V. \& Fabris V.E. 1993. Esporotricose do gato doméstico (Felis catus): transmissão humana. Revta Inst. Med. Trop. São Paulo 35(4):327-330.

Miranda L.H.M., Conceição-Silva F., Quintella L.P., Kuraiem B.P., Pereira S.A. \& Schubach T.M.P. 2013. Feline sporotrichosis: histopathological profile of cutaneous lesions and their correlation with clinical presentation. Microbiol. Infect. Dis. 36(2013):425-432.

Miranda L.H.M., Quintella L.P., Menezes R.C., Santos I.B., Oliveira R.V.C., Figueiredo F.B., Lopes-Bezerra L.M. \& Schubach T.M.P. 2011. Evaluation of immunohistochemistry for the diagnosis of sporotrichosis in dogs. Vet. J. 190:408-411.

Miranda L.H.M., Quintella L.P., Santos I.B., Menezes R.C., Figueiredo F.B., Gremião I.D.F., Okamoto T., Oliveira R.V.C., Pereira S.A., Tortelly R. \& Schubach T.M.P. 2009. Histopathology of canine sporotrichosis: a morphological study of 86 cases from Rio de Janeiro (2001-2007). Mycopathologia 168:79-87.

Rodrigues A.M., Hoog G.S., Zhang Y. \& Camargo Z.P. 2014. Emerging sporotrichosis is driven by clonal and recombinant Sporothrix species. Emerg. Microbes Infect. 3:1-10.

Romero-Martinez R., Wheeler M., Guerrero-Plata A., Rico G. \& TorresGuerrero H. 2000. Biosynthesis and functions of melanin in Sporothrix schenckii. Infect. Immun. 68(6):3696-3703.

Rosser E.J. \& Dunstan R.W. 2006. Sporotrichosis, p.608-612. In: Greene C.E. (Ed.), Infectious Diseases of the Dog and Cat. 3rd ed. Elsevier, Philadelphia.

Rossi C.N., Odaguiri J. \& Larsson C.E. 2013a. Retrospective assessment of the treatment of sporotrichosis in cats and dogs using itraconazole. Acta. Scient. Vet. 41:1112-1116.

Rossi C.N., Odaguiri J. \& Larsson C.E. 2013b. Clinical and epidemiological characterization of sporotrichosis in dogs and cats (São Paulo, Brazil). Ciênc. Agrárias 34(6):3889-3896.

Schubach T.M.P., Menezes R.C. \& Wanke B. 2012. Sporotrichosis, p.645650. In: Greene C.E. (Ed.), Infectious Diseases of the Dog and Cat. 4th ed. Elsevier, St Louis.

Souza L.L., Nacente P.S., Nobre M.O., Meinerz A.R.M. \& Meireles M.C.A. 2006. Isolation of Sporothrix schenckii from the nails of healthy cats. Braz. J. Microbiol. 37:372-374.

Téllez M.D., Batista-Duharte A., Portuondo D., Quinello C., Bonne-Hernández R. \& Carlos I.Z. 2014. Sporothrix schenckii complex biology: environment and fungal pathogenicity. Microbiology 160:2352-2365.

Vásquez-del-Mercado E., Arenas R. \& Padilla-Desgarenes C. 2012. Sporotrichosis. Clin. Dermatol. 30:437-443. 